\title{
Incidence of Violence Against Some Disabled Children in Assiut City.
}

\author{
Nessma Sh. Omer ${ }^{1}$, Hoda Diab Fahmy ${ }^{2}$, Soad Abdel-Hameed Sharkawy ${ }^{3}$ \& Naglaa Saad Abd El-aty ${ }^{3}$ \\ ${ }^{1}$ Technical Nursing Institute, Assiut University, Egypt \\ ${ }^{2}$ Professer of community Health Nursing, Faculty of Nursing, Assiut University, Egypt \\ ${ }^{3}$ Assist.Prof of community Health Nursing, Faculty of Nursing, Assiut University, Egypt
}

\begin{abstract}
Background: Children with disabilities face significant barriers to enjoying their fundamental rights. They are also denied access to basic services, such as health care and exposed to discrimination, as well as sexual, physical and psychological violence. Aim of the study: To determine the incidence of violence against some disabled children at Assiut city. Subjects and methods: Descriptive research design was utilized in this study. Multi stage random sample used to include (10\%) which represent 60 disabled pupils. The study was conducted in the following schools El-Nour school for blind pupils, El-Amal school for deaf girls in El-Arbeen district and El-Amal school for deaf boys in Assiut city. A structured interviewing questionnaire for disabled children. It include personal characteristics and exposure to violence in the previous 3 months. Results: The present study illustrated that it was found that $88.8 \%, 77.7 \%$ \& $40.0 \%$ of disabled children were exposed to physical, psychological and sexual violence respectively. Conclusion: the majority of the disabled children were exposed to violence Recommendations: Increase public awareness about disabled children rights through mass media.
\end{abstract}

\section{Key words: Violence \& Disabled Children.}

\section{Introduction}

Harkness \& DeMarco, (2016) defined violence as an act commited by a person against another person in which there is a conscious choice to act violently. Violence includes many forms as physical, psychological, sexual violence, and bullying. It is perpetrated and experienced by students, caregivers, teachers and other school staff. Disability conceptualizes it as lying "on a continuum from minor difficulties in functioning to major impacts on a person's life (Chan et al., 2016).

A physical disability covers impairments, activity limitations, and participation restrictions. Impairment is a problem in body function or structure. Physical disabilities are caused by impairments to various subsystems of the body. These can be broadly classified under the following categories (Kumer et al., 2013).

Children with developmental disabilities are a vulnerable population whose chances of being exposed to violence are greater than the chances of normally developing children. With this information it is clear that the problem needs to be addressed. It is not enough to address violence once it has already occurred. The increased chance of violence must be addressed by providing information to the parents or caregivers of this population that is most likely to prevent violence occurring to begin with (Chenaille, 2013).

Physical violence is most obvious, more severe and frequent which may cause the death of victims. It used as a punishment which aims to cause harm or discomfort to a child. Physical violence includes hitting, slapping, kicking, shaking, biting, strangling and cutting (Girmatsion et al., 2012).

Psychological violence occurs when a child's experience of being rejected as denied a sense of positive self-regard and worth, as well as isolated as removed from relationships with others, when a child's experience of being terrorized as intimidated or frightened with threats of harm (WHO, 2018).

Sexual violence has many forms as kissing, holding a child in a sexual manner, exposing a sexual part of a child, sending obscene mobile text-messages or emails to a child (Ebenuwa-Okoh, 2016).

In Egypt the number of disabled person aged more than 5 years was $10.67 \%$ of the total population. Mental retardation $(2.78 \%)$, blindness $(4.73 \%)$, deaf (3.59\%), mobility impairments $(6.32 \%)$ and $(6.59 \%)$ for other disabilities of the total number of disabled people. In Assiut governorate the disabled children aged more than 5 years represent $(11.79 \%)$ of the total population (The Census of Population \& Housing Condition, 2017).

The community health nurse jointly focused on the prevention. The goal of primary prevention is promotion of optimal parenting and family wellness. The community health nurse provide life skill training in schools ,churches and communities. Design educational program for children and their parents about methods of conflict resolution to prevent violence from occurring. The secondary prevention begins with assessment and screening. For example consistent assessment of child during health care visits will increase case finding and provide opportunities for early intervention. The goal of 
tertiary prevention reeducation and rehabilitation of violent children which can achieve by formal training in child rearing and counseling services for individuals and families. The problem of violence cannot be managed by nurses alone, but rather in combination with other professionals. This interdisciplinary approached leads to optimal outcomes (Nies \& Mcewen, 2015).

\section{Significant of the study}

Children with disabilities are three to four times more likely to be victims of violence than their peers without disabilities. This qualitative research has identified multiple forms of discrimination faced by children with disabilities, including stigma, denial of access to school, lack of support for special educational needs and reduced employment prospects. Poverty, gender inequalities and disability have been shown to increase the risk of violence and discrimination against children in some contexts. (Nelson \& Bornman 2014).

In Assuit governorate (79.5\%) of disabled children were exposed to psychological violence; while $(66.4 \%)$ were exposed to physical violence. $(27.6 \%)$ were exposed to sexual violence. (44.9\%) of them suffered from internalizing behavioral problems such as withdrawal, anxiety and depression. While $(17.0 \%)$ of them suffered from externalizing behavioral problems such as delinquent and aggressive behaviors(Omer et al., 2014) .

\section{Objective of the study}

Determine the incidence of violence against disabled children at Assiut city.

\section{Aims of the study}

1. Determine the different types of violence against disabled children at Assiut city.

2. Determine the place of violence against disabled children at Assiut city.

3. Determine the perpetrators of violence against disabled children at Assiut city.

\section{Research questions}

1. What are the types of violence against disabled children?

2. Where did the disabled children exposed to violence?

3. Who were perpetrators of violence against the disabled children?

\section{Subjects \& Methods \\ Research design}

Descriptive research design was utilized in this study. Study Settings

There are only four schools for disabled children at assiut city. The study setting conducted in three disabled children school. It include El-Nour school for blind pupils in El-Arbeen district, El-Amal school for deaf and dumb females in El-Arbeen district, ElAmal school for deaf and dumb males in Assiut city, except El-Tarbia El - Fikria school which had intellectual disabilities because it is very difficult for the researcher to find appropriate way for communication with them.

\section{Study subjects}

The target population of the study was disabled children both (boys and girls) aged approximately between 6 to 18 years. Primary school ranged from grade one to grade sixth in El-Nour school for blinded pupils. El-Amal school for deaf and dumb pupils ranged from one grade to eight grades. Preparatory schools ranged from first to third grade for both El-Nour and El-Amal schools.

\section{Sample and sampling}

The total disabled pupils in the previous settings were 599 pupils, Multi stage random sample was used in the study. The sample was included $10 \%$ of disabled pupils from the total number of pupils which represent 60 pupils.

\section{Study tools}

Tool (1): A structured interviewing questionnaire for child:

Was divided into two parts:

Part (1): It included questions regarding personal characteristics of children such as (name, sex, age, education level, school name, residence).

Part (2): It included questions regarding exposure to violence in the previous 3 months such as: forms of violence which classified into three forms the first one is physical violence such as hitting, kicking, beating, and etc...., The second form psychological violence such as humiliation, social rejection, isolation and etc....and the third form is sexual violence such as unwanted sexual touch, forcing to touch someone sexually and etc..... In addition to questions regarding places, perpetrators.

\section{Scoring system}

It was designed to be collected from disabled children. It consisted of 38 items. The answer were coded (yes $=1)$ and $($ no $=0)$. The total score was (38) grades. The score was calculated by summing up $(0=$ non exposed) and ( $\geq 1=$ exposed).

\section{Methodology}

I-Administrative phase

An official letter approval was obtained from the Dean of Faculty of Nursing, Assiut University, to Directorate of Education and from the Directorate to Central Agency for Public Mobilization and Statistics after that to Centralized management of security finally to directors of schools. The letter included a permission to carry out the study. Before carrying out this study, the researcher received the sign language 
training in Assiut University to communicate with deaf and dump student.

\section{II-Pilot Study}

After developing the tool, It was carried on (10\%) of pupils who were excluded from the study. The aim of the pilot study is to test the feasibility, clarity and to estimate the required time to fill the questionnaire. Based on the results of pilot study the necessary modification was done and the questionnaire was reconstructed for ready to use.

\section{Validity}

To ensure the validity of these tools, it was checked and revised by panel of 5 experts from community health nursing staff at Assiut University who reviewed the tools for clarity, relevance and comprehensiveness.

\section{Reliability}

The value of $\alpha$ - cronbach methods for Alabama Parenting questionnaire scale was 0.641 at significant level at $\mathrm{P}<0.01$, this indicates high index of questions' reliability and their efficiency on expressing violence against disabled children.

\section{III- Data collection Phase}

\section{Ethical Consideration}

Research proposal was approved from Ethical Committee in the Faculty of Nursing. There is no risk for study subject during application of research. The study will follow common ethical principles in clinical research. Oral consent was obtained from guidance that is willing to participate in the study, after explaining the nature and purpose of the study. Confidentiality and anonymity were assured. Study subject have the right to refuse or participate and withdraw from the study without any rational reason at any time. Study subject privacy was considered during collection of data.

\section{Field Work}

The researchers collected the data from all disabled pupils during the period from the mid of October 2017 until the mid of December 2017. Data was collected from pupils from 2 p.m. to 7p.m, two days / week. The average number of pupils was 6- 8 pupils / day. The length of time needed to complete each sheet was about 15- 20 minute.

\section{Statistical Analysis}

The data obtained were reviewed, prepared for computer entry, coded, analyzed and tabulated. Descriptive statistics (i.e., percentage, mean and standard deviation, etc) was done using computer program SPSS version 16. 


\section{Results}

Table (1): Distribution of some demographic data of disabled children at Assiut city, 2018( $n=60)$

\begin{tabular}{|l|c|c|}
\hline \multicolumn{1}{|c|}{ Some demographic data } & No. & \% \\
\hline Age: (years) & & \\
\hline$<12$ years & 31 & 51.7 \\
\hline$\geq 12$ years & 29 & 48.3 \\
\hline Mean \pm SD (Range) & \multicolumn{2}{c|}{$11.97 \pm 3.77$} \\
\hline Sex: & \multicolumn{2}{c|}{} \\
\hline Male & 34 & 56.7 \\
\hline Female & 26 & 43.3 \\
\hline School level: & & \\
\hline Primary & 43 & 71.6 \\
\hline Preparatory & 17 & 28.3 \\
\hline Residence: & & \\
\hline Rural & 54 & 90.0 \\
\hline Urban & 6 & 10.0 \\
\hline
\end{tabular}

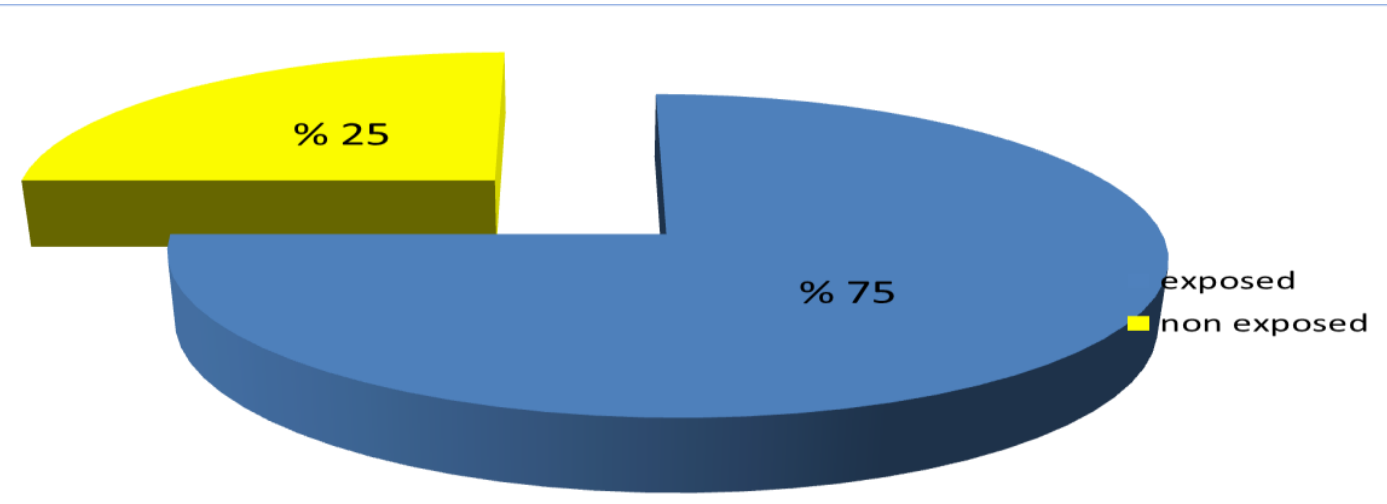

Figure (1): The incidence of violence among some disabled children at Assiut city, $2018(\mathrm{n}=60)$

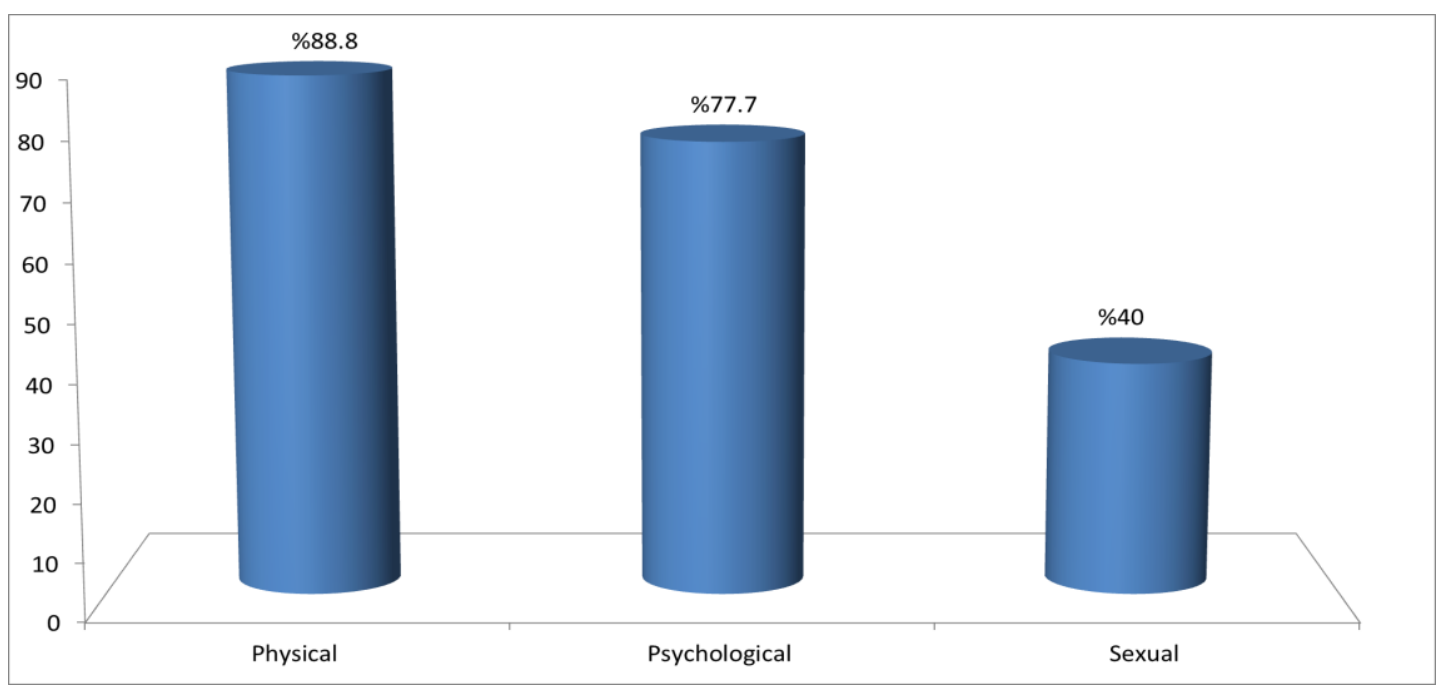

Figure (2): The incidence of different types of violence among some disabled children at Assiut city, 2018 
Table (2): The incidence of forms of physical violence among exposed disabled children at Assiut city, 2018.

\begin{tabular}{|l|c|c|}
\hline \multicolumn{1}{|c|}{ Forms of physical violence } & Yes (n= 40) \\
\cline { 2 - 3 } \multicolumn{1}{c|}{} & No. & \% \\
\hline Beating & 30 & 75.0 \\
\hline Burning & 8 & 20.0 \\
\hline Slapping on their faces & 14 & 35.0 \\
\hline A bad taste put in their mouth & 4 & 10.0 \\
\hline Depriving of food & 4 & 10.0 \\
\hline Depriving of sleep & 0 & 0.0 \\
\hline Restricting & 6 & 15.0 \\
\hline Kicking & 14 & 35.0 \\
\hline Twisting their arm or leg & 12 & 30.0 \\
\hline Biting & 7 & 17.5 \\
\hline Throwing them with something & 10 & 25.5 \\
\hline Muting their breath with their hand or pillow & 5 & 12.5 \\
\hline Trapping them in a dark place & 2 & 5.0 \\
\hline Pulling their hair & 5 & 12.5 \\
\hline Cutting their hair & 1 & 2.5 \\
\hline Hitting them by pressing on their bodies & 7 & 17.5 \\
\hline Threatening them with weapons or by a knife & 7 \\
\hline Forcing them to sit or stand in an uncomfortable position & 7 & 17.5 \\
\hline Inserting a needle in their bodies & 4 & 10.0 \\
\hline Forcing them to take illegal drugs & 5 & 12.5 \\
\hline Forcing them to smoke & 4 & 10.0 \\
\hline More than one answer & 5 & 12.5 \\
\hline
\end{tabular}

\# More than one answer.

Table (3): The incidence of forms of psychological violence among exposed disabled children at Assiut city, 2018.

\section{\#Forms of psychological violence}

Feeling estranged and being unfriendly to them.

Reproaching them for simple mistakes.

Forcing them to do things they don't like.

Asking them to do things without discussion.

Depriving them from the thing they like (picnic, a game and etc...).

Calling them out by undesirable descriptions

Depriving them of their pocket money.

Criticizing them on the way they do something.

Interrupting them for a long period.

Didn't listen to them when they talk about themselves.

Comparing them with others to reduce your business.

Threatening to send them out of home.

Threatening them with ghosts and evil spirits.

\begin{tabular}{|c|c|}
\hline \multicolumn{2}{|c|}{ Yes $(\mathbf{n}=\mathbf{3 5})$} \\
\hline No. & \% \\
\hline 17 & 48.5 \\
\hline 17 & 48.5 \\
\hline 6 & 17.1 \\
\hline 14 & 40.0 \\
\hline 8 & 22.9 \\
\hline 15 & 42.9 \\
\hline 1 & 2.9 \\
\hline 3 & 8.6 \\
\hline 6 & 17.1 \\
\hline 7 & 20.0 \\
\hline 4 & 11.5 \\
\hline 2 & 5.8 \\
\hline 1 & 2.9 \\
\hline
\end{tabular}

\# More than one answer.

Table (4): The incidence of forms of sexual violence among exposed disabled children at Assiut city, 2018.

\begin{tabular}{|l|c|c|}
\hline \multicolumn{1}{|c|}{ Forms of sexual violence } & \multicolumn{2}{c|}{ Pretest (n= 18) } \\
\cline { 2 - 3 } & No. & \% \\
\hline Trying to embrace and kiss them & 13 & 72.3 \\
\hline Insulting them by sexual terms & 14 & 77.8 \\
\hline Forcing them to touch the abuser's genitals & 12 & 66.7 \\
\hline Forcing them to see sexual scenes & 8 & 44.5 \\
\hline
\end{tabular}

\# More than one answer.

Vol , (7) No, (16) March, 2019 


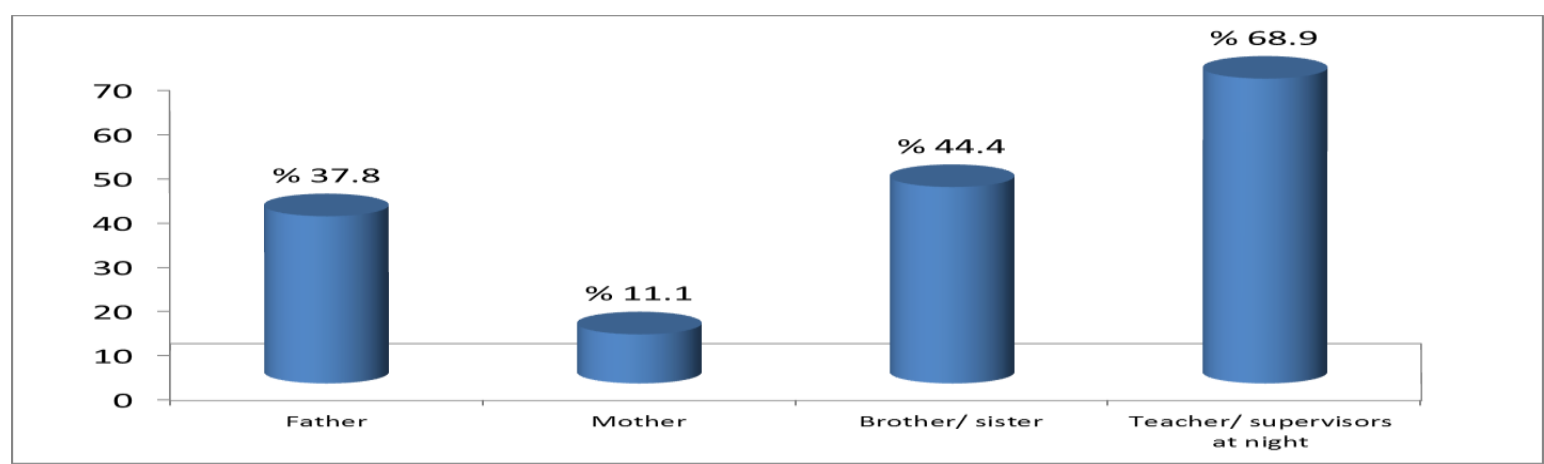

Figure (3): Distribution of the exposed disabled children regarding the perpetrators of violence at Assiut city, $2018(n=45)$

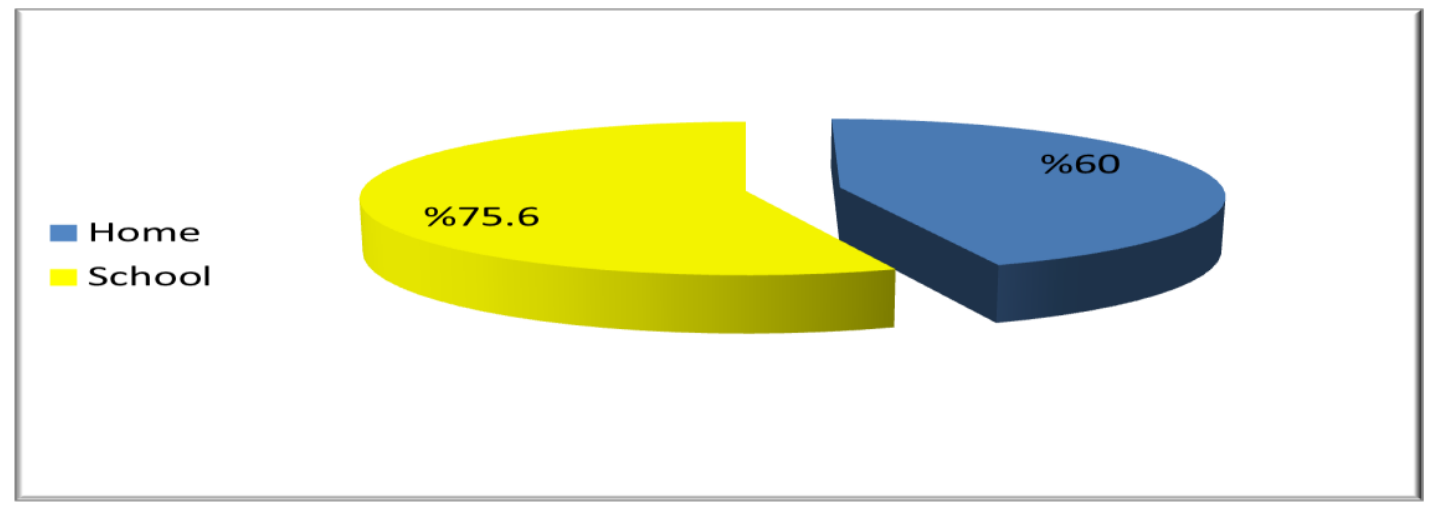

Figure (4): Distribution of the exposed disabled children regarding the places of violence at Assiut city, 2018 $(n=45)$

Table (5): Relation between exposure to violence and their age, sex and residence among the studied disabled children at Assiut city, 2019.

\begin{tabular}{|c|c|c|c|c|c|}
\hline & \multicolumn{2}{|c|}{$\begin{array}{c}\text { Exposed } \\
(n=45)\end{array}$} & \multicolumn{2}{|c|}{$\begin{array}{l}\text { Not exposed } \\
\quad(n=15)\end{array}$} & \multirow[t]{2}{*}{ P-value } \\
\hline & No. & $\%$ & No. & $\%$ & \\
\hline \multicolumn{5}{|l|}{ Age: (years) } & \multirow{3}{*}{$0.005^{*}$} \\
\hline$<12$ years & 28 & 90.3 & 3 & 9.7 & \\
\hline$\geq 12$ years & 17 & 58.6 & 12 & 41.4 & \\
\hline \multicolumn{5}{|l|}{ Sex: } & \multirow{3}{*}{0.133} \\
\hline Male & 28 & 82.4 & 6 & 17.6 & \\
\hline Female & 17 & 65.4 & 9 & 34.6 & \\
\hline \multicolumn{5}{|l|}{ Residence: } & \multirow{3}{*}{0.318} \\
\hline Rural & 40 & 72.7 & 15 & 27.3 & \\
\hline Urban & 5 & 100.0 & 0 & 0.0 & \\
\hline
\end{tabular}

Table (1): Shows some demographic data of disabled children, it was found that the mean age of them was 11.97 \pm 3.77 . Concerning their sex it was observed that more than half of them $(56.7 \%)$ were males. As regard school level; it was found that less than three quarters $(71.6 \%)$ of disabled children were in primary school. Regarding to residence the majority $(90 \%)$ of disabled children was living in rural area.
Fig (1): Clear that the three quarters $(75 \%)$ of the disabled children were exposed to violence.

Fig (2): Shows the incidence of different types of violence among some disabled children it was found that $88.8 \%, 77.7 \%$ \& $40.0 \%$ of disabled children were exposed to physical, psychological and sexual violence respectively. It was found that more than one type of violence was reported for the child. 
Table (2): This table shows that the incidence of forms of physical violence among some disabled children, about more than two thirds $(75 \%)$ of disabled children were physically beaten while $35 \%$, $35 \% \& 20 \%$ were kicked, slapped on their faces and burned respectively.

Table (3): This table illustrates the incidence of forms of psychological violence among exposed disabled children, more than two fifths $(48.5 \%)$ of disabled felled estranged and being unfriendly to them and reproached for simple mistakes. In addition to slightly less than one fifth $(24.9 \%)$ were called out by undesirable descriptions.

Table (4): Illustrates the incidence of the studied disabled children regarding the forms of sexual violence; it was observed that $66.7 \%$ of disabled children were forced to touch the abuser's genitals.

Fig (3): Illustrates the distribution of the exposed disabled children regarding the perpetrators of violence, it was found that $37.8 \%$ were exposed to violence by father while more than two thirds $(68.9 \%)$ of them were exposed to violence by teachers or supervisors at night.

Fig (4): Illustrates the distribution of the exposed disabled children regarding the places of violence. It was noticed that more than three quarters $(75.6 \%)$ of disabled children were exposed to violence at school while less than two thirds $(60 \%)$ of them were exposed to violence at home. Some children were exposed to violence in the both place.

Table (5): Shows the Relation between exposure to violence and their age, sex and residence among the studied disabled children. It was found that the majority $(90.3 \%)$ of disabled children who aged $<12$ years were exposed to violence. In addition to the majority $(82.4 \%)$ of males were exposed to violence.

\section{Discussion}

ziolence is both an individual and a societal issue that is steadily increasing in the world. Exposure to violence in childhood, exploitation, and negligence leave deep scars and adversely affect mental health (Gür \& Albayrak, 2015).

The mean age of disabled pupils was $11.97 \pm 3.77$. These findings are partially supported by Gopalan et al., (2014) who conducted the study at India about sociodemographic and clinical features of children with intellectual disability and their parents The mean age of the children was found to be $(9.48 \pm 2.17)$ years and the age ranged from 5 to 16 .

These can be rationalized by in Assiut; there is limited numbers of schools for disabled children and most of them located in the city. The flow of disabled children is large, so the schools accept older children. Concerning gender of disabled pupils; it was observed that more than half of them were males.
These findings may be explained by parents often don't let their disabled daughters go to school, either because they may have shameful feeling. Additionally, in upper Egypt families provide more care for males than female. This finding in accordance with Also Heykyung \& Eun (2009) who conducted the study in South Korea about caregivers burden and social support among mothers raising children with developmental disabilities reported that more half of disabled children were males.

As regard residence; it was observed that the majority of them was living in rural area. These findings are in accordance with Ali (2009) who conducted his study at Assiut city about effect of disability on physical growth of primary school children and reported that were higher in rural than urban areas.

Concerning to the violence exposure the findings of the present study summarize that three quarters of the disabled children were exposed to violence. Furthermore the incidence of different types of violence. It was found that the majority of disabled children were exposed to physical and psychological violence while two fifths were exposed to sexual violence.

These findings disagree with the results of Chan et al., (2016) who conducted the study about children with disability are more at risk of violence victimization at Chinese and mentioned that more than half of disabled children were exposed to violence. Also they show that more than one fifths of the disabled children were exposed to physical violence while $14 \%, 5 \%$ of them were exposed to sexual and psychological respectively.

The explanation for these findings due to most disabled children with disabilities may depend on others to meet some or all of their basic needs. Care providers, including family and school caregivers, may be involved in close, frequent contact in the most intimate and personal parts of the individual's life (e.g., assistance with bathing, toileting, changing clothes, other hygiene-related tasks), which can increase the opportunity for sexual or other abusive acts. Persons with disabilities may not understand the difference between sexual and non-sexual touches.

Concerning to forms of physical violence it was pointed out that about more than two thirds of them were physically beaten while more than one third were kicked and slapped on their faces.

This findings are partially in line with Akram \& Shafiq (2014) who mentioned that corporal punishment was the most common type mentioned by disabled children. Other forms were noticed such as hitting with shoes and slapped on their faces.

Regarding to forms of psychological violence it was noticed that more than two fifths felled estranged and 
being unfriendly to them and reproached for simple mistakes. In addition to less than one fifth were called out by undesirable descriptions.

These findings was agree with The african child policy forum (ACPF) (2011) which conducted the study at Ethiopia to assess violence against disabled children and reported that one third of them were called out by undesirable description, and one quarter were shouted or glared at or embarrassed.

Concerning forms of sexual violence in the present study; it was observed that more than two thirds of disabled pupils were forced to touch the abuser's genitals.

These findings disagree with the results of Kucuk et al., (2017) who conducted the study on children with intellectual disability at Turkey about increasing awareness of protection from sexual abuse in children with mild intellectual disabilities and found that about one third of disabled children forced touch inappropriate body parts

Concerning to places and perpetrators it was found that more than two thirds of disabled children were exposed to violence by teachers or supervisors at night, while three quarters of them were exposed to violence at school.

The explanation for these findings could be teaching staff that lack training and background on disability can be quick to lash out at disabled children either because of lack of job satisfaction or lack of understanding about the limitations of the children. Teachers were more contact with disabled children through establishing an internal in their school. There are no regulations and policies to stop violence against disabled children. Also lack or absence of the social workers, psychiatrist and community health nurse in schools. There isn't report mechanism used at schools to report disabled child, teachers and family care giver to complain about violence.

The current study showed that the majority of disabled children who aged $<12$ years were exposed to violence. In addition to the majority of males were exposed to violence. This may be explained by in the Egyptian community, males are involved in social activities that predispose them to violence. Younger children exposed to violence more than older because of they unable to defend themselves.

These findings of the results supported by Chan, et al., (2016) who conducted the study on disabled children mentioned that children with disability are more likely to be exposed to violence at younger ages and male disabled children are more likely to be exposed to violence than females

\section{Conclusion}

Based on the results of the present study, it was noticed that the disabled children were exposed to more than one type of violence. Also, it was found that more than two thirds of disabled children were exposed to violence at school while less than two thirds of them were exposed to violence at home.

\section{Recommendations}

Based on the findings, the following recommendations are suggested:

1. Increase public awareness about disabled children rights through mass media.

2. Health education programs about violence should be implemented for caregivers and teachers about violence against disabled children and its hazards.

3. Establish procedures and staff training on how to identify and report suspected violence against disabled children.

\section{References}

1. Akram, B., \& Shafiq, S., (2014):Maltreatment among Deaf, their Non-Disabled Siblings and Hearing Children: Prevalence and Prevention, European Academic Research, 1(10): 2963:2986.

2. Ali, E. (2009): Effect of Disability on Physical Growth of Primary School Children in Assiut city, Thesis Master Degree in Community Health Nursing, Assiut University, pp.72-73.

3. Chan, K., Emery, C., \& Patrik, I., (2016): Children with Disability Are More at Risk of Violence Victimization Evidence from a Study of School-Aged Chinese Children journal of interpersonal violence 31(6)33:45.

4. Chenaille, T., (2013): Abuse of developmentally disabled children: a preventative program, Thesis Master Degree in of Arts in Social Policy, Empire State College, State University of New York, pp.13:36.

5. Ebenuwa-Okoh, E., (2016): Parents Educationists Perceptions on the Forms and Consequences of Child Sexual Abuse, Pyrex Journal of Psychology and Counseling 2 (2) pp. 005:010.

6. Girmatsion, F., Abeb, E, \& Mulusew, G., (2012): Intimate Partner Physical Violence among Women in Shimelba Refugee Camp, Northern Ethiopia, Public Health Journal, 12:511.

7. Gopalan, R., Sharma, R., \& Unnikrishnan, M., (2014): Socioemographic and Clinical Features of Children with Intellectual Disability and Their Parents-an Indian Study, International Neuropsychiatric Disease Journal,2(6): 289-302.

8. Gür, K., \& Albayrak, S., (2015): Exposure to Violence of Secondary School Children with 
Visual Impairment, Journal of Interpersonal Violence, (26):78:79.

9. Harkness \& DeMarco, (2016): violence and abuse, Community and Public Health Nursing Evidence for Practice, ch16, $2^{\text {nd }}$ ed., Wolters Kluwer, China, Pp. 308:309.

10. Heykyung, O., \& Eun K., (2009): Caregiver Burden and Social Support among Mothers Raising Children with Developmental Disabilities in South Korea , International Journal of Disability, Development and Education, 56(2), 149-167.

11. Kucuka, S., Platinb, N., \& Erdemc, E., (2017): Increasing awareness of protection from sexual abuse in children with mild intellectual disabilities: An ducation study, Applied Nursing Research Journal, 38: 153:158.

12. Kumer, B., Vinod, K., \& Ray, A., (2013): Design of Three Wheeler Vehicle for Phsically Challenged People, SASTech - Technical Journal, 12(1):81-90.

13. Nelson, D., \& Bornman, J., (2014): Stop Violence against People with Disabilities, Centre for Human Rights faculty of Law, University of Pretoria, South Africa available at (www.pulp.up.ac.za/pdf/2014_12/2014_12.pdf).

14. Nies, M., \& McEwen, M., (2015): Community $\&$ Public Health, Nursing, Violence, ch.(27), $6^{\text {th }}$ ed.,China,p.p.552-553.

15. Omer, S., Kotb, A., El-serogy, M., \& ElHoufy, A., (2014): Violence against Disabled Children Assiut governorate, Assiut Scientific Nursing Journals, 2(4):1-9.

16. The African child policy forum ACPF (2011): Violence against Children with Disabilities in Africa; available at (www. africanchildforum.org).

17. The census of population \& housing condition (2017): Arab Republic of Egypt, Egyptian central agency or public mobilization and statistics , available at (http://www.capmas.gov.eg/database.aspx?pare ntid $=1782 \&$ free $=1$ )

18. World Health organization (WHO) (2018): Violence against Disabled children, Available at

(http://www.who.int/mediacentre/factsheets/viol ence- against-disabled-children/en/) 